\title{
Case Report: A Stepwise Multidisciplinary Rehabilitation Approach of Central Pontine and Extra Pontine Myelinosis in Locked-in Syndrome: A Case Report
}

\author{
Natiara Mohamad Hashim ${ }^{1^{*}}$ (i), Fatimah Ahmedy² (iD, Wan Najwa Wan Mohd Zohdi' ${ }^{1}$ (D) Khadijah Mahmud $^{1}$ (i) \\ 1. Department of Rehabilitation Medicine, Faculty of Medicine, Universiti Teknologi MARA, Sungai Buloh, Malaysia. \\ 2. Rehabilitation Medicine Unit, Faculty of Medicine \& Health Sciences, Universiti Malaysia Sabah, Kota Kinabalu, Malaysia.
}

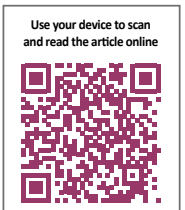

Citation: Mohamad Hashim N, Ahmedy F, Wan Mohd Zohdi WN, Mahmud K. A Stepwise Multidisciplinary Rehabilitation Approach of Central Pontine and Extra Pontine Myelinosis in Locked-in Syndrome: A Case Report. Iranian Rehabilitation Journal. 2021; 19(2):215-220. http://dx.doi.org/10.32598/irj.19.2.1327.1

doi http://dx.doi.org/10.32598/irj.19.2.1327.1

Article info:

Received: 17 Jan 2021

Accepted: 20 Jun 2021

Available Online: 01 June 2021

\section{Keywords:}

Locked-in syndrome, Extra pontine myelinosis, Multidisciplinary rehabilitation

\section{ABSTRACT}

Central Pontine Myelinosis (CPM) and Extra Pontine Myelinosis (EPM) are debilitating conditions, resulting from the rapid correction of hyponatremia. The outcome and prognosis of this medical condition are variable; mainly involving functional decline from neuromusculoskeletal upset. An intensive, multidisciplinary rehabilitation has played an essential role in facilitating and hasten recovery, promoting a favorable outcome. We reported our experience in rehabilitating a patient with a rare condition of comorbid CPM and EPM. The reported patient presented with disabling Locked-in Syndrome (LIS) and Parkinsonism movement disorder. We highlighted the stepwise rehabilitation approach according to Patterson and Grabois Motor Recovery scale for LIS in preventing and reversing the complications and disabilities caused by CPM and EPM that may facilitate favorable therapeutic outcomes.

\footnotetext{
* Corresponding Author:

Natiara Mohamad Hashim

Address: Department of Rehabilitation Medicine, Faculty of Medicine, Universiti Teknologi MARA, Sungai Buloh, Malaysia.

Tel: +60 (361) 265000

E-mail: natiara@uitm.edu.my
} 


\section{Highlights}

- Patients with pontine and extra-pontine myelinosis may encounter debilitating impairments and dysfunction.

- Pontine and extra-pontine myelinosis may possess a desirable prognostic outcome if rehabilitation is administered early.

- The rehabilitation intervention should follow a stepwise multidisciplinary approach.

\section{Plain Language Summary}

This case report highlighted a rare debilitating clinical condition. It may be potentially reversible if holistic rehabilitation management is administered early. The rehabilitation intervention should be in a stepwise-multidisciplinary approach tailored to patients' impairments and dysfunction resulting from this disease.

\section{Introduction}



he Osmotic Demyelination Syndrome (ODS) is initially characterized as noninflammatory demyelination. This condition involves the basis pontis and other areas on the central nervous system that may be affected symmetrically, namely external capsules, caudate nucleus, putamen, thalamus, and other different structures [1]. Two widely recognized ODS consist of Central Pontine Myelinosis (CPM) and Extra Pontine Myelinosis (EPM); they may occur isolated from each other or concomitantly in $50 \%$ of the cases [1]. ODS's pathophysiology is believed to be the fluctuating osmotic forces causing cellular edema secondary to the rapid and overcorrection of hyponatremia; results in fibre tract compression and demyelination [1]. The clinical presentations of CPM and EPM vary, depending on the involved structures. The usual presentation of this condition is a Locked-in Syndrome (LIS). It is characterized by anarthria, quadriplegia with bulbar involvement with the preservation of eyeball movement, and variable movement disorder characterized by Parkinsonism, dystonia, mutism, and catatonia [1]. The outcome and prognosis of CPM and EPM are heterogeneous [2]. We highlighted the stepwise rehabilitation approach according to Patterson and Grabois Motor Recovery Scale (PGMRS) for LIS. This motor scale serves as a guidance in tools addresses preventing and reversing the complications and disabilities caused by CPM and EPM that may facilitate a desirable therapeutic outcome.

\section{Case Report}

A 40year-old male initially presented to the hospital with a one-week history of acute severe gastroenteritis symptoms. This condition caused him severe hypona- tremia (sodium level of $117 \mathrm{mmol} / \mathrm{L}$ ) and hypokalemia (potassium level of $2.7 \mathrm{mmol} / \mathrm{L}$ ) without a history of chronic alcoholism. Other blood investigations were unremarkable. His electrolytes imbalance was corrected to a sodium level of $128 \mathrm{mmol} / \mathrm{L}$ and a potassium level of $3.0 \mathrm{mmol} / \mathrm{L}$ with the intravenous infusion of sodium chloride and a slow infusion of potassium chloride within 48 hours of admission. He was then discharged well with healthy electrolyte levels.

However, he was presented again to the emergency department two days after discharge with a low Glasgow Coma Scale (GCS) of E3, V5, and M6. He also manifested new neurological symptoms of coarse resting tremor with gait ataxia. Upon examination, all four limbs' muscle power was graded as five according to the Medical Research Council (MRC) grading system; there was no sensory loss, cerebellar signs were negative, hyper-reflexes, intact proprioception, and the plantar response were downgoing bilaterally. Blood investigations revealed a sodium level of $134 \mathrm{mmol} / \mathrm{L}$ with a potassium level of $3.1 \mathrm{mmol} / \mathrm{L}$. Upon admission to the ward, his condition progressively deteriorated in one-week duration. Parkinsonism symptoms started to appear with the evidence of extrapyramidal signs of a generalized severe limbs cogwheel and lead pipe rigidity, truncal rigidity, hypomimia, and resting tremor. Within several days, symptoms evolved to a LIS by the evidence of quadriparesis, dysphagia, and anarthria. Eye blinking and eyeball movement were preserved. Otherwise, his conscious level remained intact.

Due to symptoms progression, he was subjected to further biochemical, radiological, and electrophysiological investigations. The relevant results were as follows: serum electrolytes level, copper, and ceruloplasmin were healthy. Brain Magnetic Resonance Imaging (MRI) 


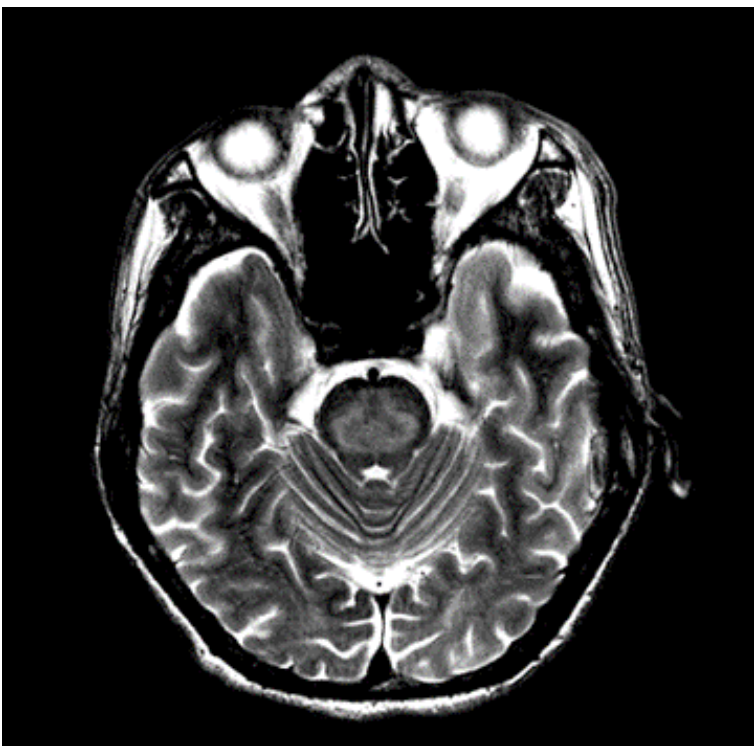

Iranian Rehabilitation Journa

Figure 1. Hyperintense area in pons in T2-weighted MRI

showed abnormal signals at pons (Figure 1), bilateral putamen, caudate nucleus, and lateral aspect of thalami (Figure 2). Nerve Conduction Studies (NCS) revealed prolonged Central Motor Conduction Time (CMCT) on the right cortical stimulation recording over the left upper limb. Motor Evoked Potential (MEP) amplitudes in the left lower limb on right cortical stimulation were reduced per normal CMCT. Electroencephalogram (EEG) and cerebrospinal fluid studies presented healthy data. Considering the history of hyponatremia's vigorous correction, consistent with the clinical findings and investigations, the diagnosis of CPM and EPM was established.

Upon review by the rehabilitation team, he was physically disabled due to severe generalized rigidity and quadriparesis with an MRC grade of 0 to 1 ; the decerebrate posturing of the limbs; dysphagia, and anarthria. The only communication mode was by answering 'Yes' or 'No' to closed-ended questions; i.e., indicated by eye blinking, which limited the full cognition assessment. The study patient's clinical findings are summarized in Table 1.

Our rehabilitation strategies were tailored in a stepwise approach according to the progression of the patient's clinical condition. This classification guided us in setting appropriate short-term rehabilitation goals and designing a customized rehabilitation program. Table 2 summarizes the stepwise approach divided into 3 phases according to PGMRS, with different short-term rehabilitation goals and interventions.

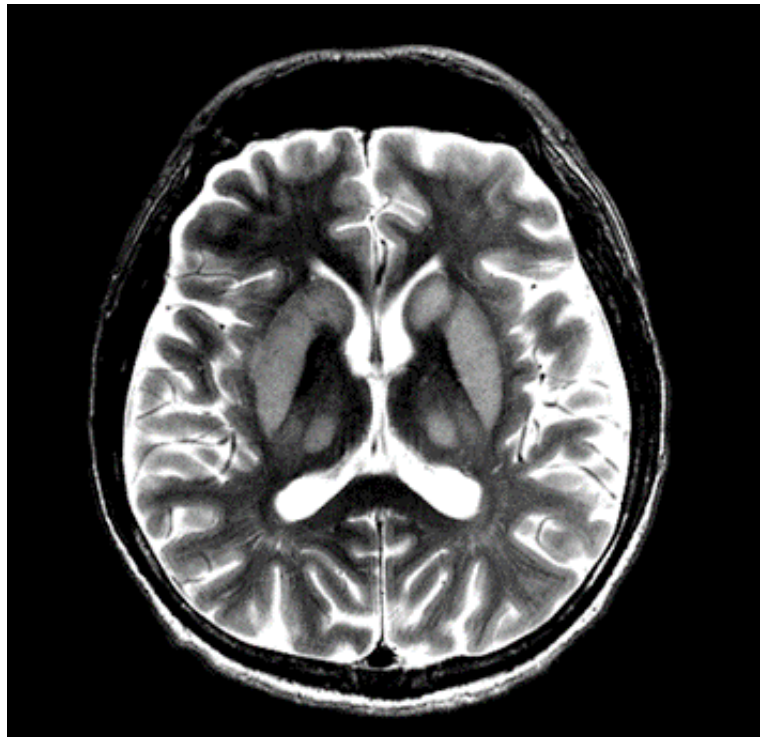

Iranian Rehabilitation Journa

Figure 2. Hyperintense areas at the bilateral putamen, caudate nucleus, and lateral aspect of thalami in T2-weighted MRI

Given the very disabling symptoms of severe Parkinsonism with generalized whole body rigidity and stiffness, pharmacotherapy with Tablet Madopar 250mg 8-hourly was initiated. Neurological and functional improvements were detected in weeks upon the initiation of pharmacotherapy concomitantly with slow stream rehabilitation interventions. Generalized severe limbs and trunks rigidity, stiffness, and resting tremor slowly became less apparent. Furthermore, more voluntary movements of the limbs, as well as the facial and oromotor muscles were observed. The reported patient appeared less hypomimia and could produce simple verbal words. Further objective assessments were more feasible at this point due to symptoms improvement, as demonstrated in Table 1. Considering the observed marked improvements, stepwise re-conditioned intensive, multidisciplinary rehabilitation was instituted, focusing more on improving mobility and overall re-conditioning (Table 2).

At the end of the interventions, he successfully ambulated without using any walking aids, communicated well with full complex sentences, and achieved full independence in daily living activities. He was functioning very well and discharged home after two months of intensive multidisciplinary rehabilitation.

\section{Discussion}

The diagnosis of ODS in the reported patient was strongly associated with the rapid correction of hyponatremia. Besides, it was supported by the clinical presentations of LIS and Parkinsonism, MRI findings, and 
Table 1. Outcome measures during the provided multidisciplinary rehabilitation program for LIS

\begin{tabular}{|c|c|c|c|c|c|c|}
\hline Outcome Measures & \multicolumn{2}{|c|}{ Initial } & \multicolumn{2}{|c|}{1 Month } & \multicolumn{2}{|c|}{2 Months } \\
\hline $\begin{array}{l}\text { Medical Research } \\
\text { council : } \\
\text { 1. Shoulder } \\
\text { 2. Elbow } \\
\text { 3. Wrist } \\
\text { 4. Finger } \\
\text { 5. Hip } \\
\text { 6. Knee } \\
\text { 7. Ankle }\end{array}$ & $\begin{array}{l}\text { Right } \\
1 \\
1 \\
1 \\
0 \\
1 \\
1 \\
0\end{array}$ & $\begin{array}{c}\text { Left } \\
0 \\
1 \\
0 \\
1 \\
0 \\
1 \\
0\end{array}$ & $\begin{array}{l}\text { Right } \\
3 \\
4 \\
2 \\
3 \\
3 \\
3 \\
2\end{array}$ & $\begin{array}{l}\text { Left } \\
3 \\
4 \\
3 \\
2 \\
3 \\
3 \\
2\end{array}$ & $\begin{array}{l}\text { Right } \\
4 \\
4 \\
5 \\
4 \\
4 \\
5 \\
3\end{array}$ & $\begin{array}{l}\text { Left } \\
4 \\
5 \\
4 \\
3 \\
4 \\
5 \\
4\end{array}$ \\
\hline Ankle ROM & $\begin{array}{l}\text { Contracture at } \\
20-30 \text { degree } \\
\text { plantarflexion }\end{array}$ & $\begin{array}{l}\text { Contracture at } \\
15-20 \text { degree } \\
\text { plantarflexion }\end{array}$ & $\begin{array}{l}\text { PROM achieved } \\
\text { at } 10-15 \text { degree } \\
\text { dorsiflexion }\end{array}$ & $\begin{array}{l}\text { PROM achieved } \\
\text { plantigrade }\end{array}$ & $\begin{array}{l}\text { PROM at planti- } \\
\text { grade }\end{array}$ & $\begin{array}{l}\text { PROM at 0-5 } \\
\text { degree dorsi- } \\
\text { flexion }\end{array}$ \\
\hline $\begin{array}{l}\text { Motor Assessment } \\
\text { Scale }\end{array}$ & \multicolumn{2}{|c|}{0} & \multicolumn{2}{|c|}{13} & \multicolumn{2}{|c|}{51} \\
\hline $\begin{array}{l}\text { Modified Barthel } \\
\text { Index }\end{array}$ & \multicolumn{2}{|c|}{2} & \multicolumn{2}{|c|}{27} & \multicolumn{2}{|c|}{100} \\
\hline Modified Rankin Scale & \multicolumn{2}{|c|}{5} & \multicolumn{2}{|c|}{4} & \multicolumn{2}{|c|}{1} \\
\hline $\begin{array}{l}\text { Patterson and Grabois } \\
\text { Motor Recovery scale }\end{array}$ & \multicolumn{2}{|c|}{1} & \multicolumn{2}{|c|}{3} & \multicolumn{2}{|c|}{4} \\
\hline Berg Balance Scale & \multicolumn{2}{|c|}{ NT } & \multicolumn{2}{|c|}{ NT } & \multicolumn{2}{|c|}{52} \\
\hline 6-Min Walking Test & \multicolumn{2}{|c|}{ NT } & \multicolumn{2}{|c|}{ NT } & \multicolumn{2}{|c|}{240 metres } \\
\hline Grip strength & \multicolumn{2}{|c|}{ NT } & \multicolumn{2}{|c|}{ NT } & \multicolumn{2}{|c|}{ RT: 20 kg; LT: 10 kgs } \\
\hline Box and Blog Test & \multicolumn{2}{|c|}{ NT } & \multicolumn{2}{|c|}{ NT } & \multicolumn{2}{|c|}{ RT: 50 Blocks; LT: 48 Blocks } \\
\hline Swallowing & \multicolumn{2}{|c|}{ Total Ryles tube feeding } & \multicolumn{2}{|c|}{$\begin{array}{l}\text { Ryles tube: } \\
\text { The trial of thin fluids and semi- } \\
\text { solid food }\end{array}$} & \multicolumn{2}{|c|}{$\begin{array}{l}\text { Normal oral intake with all food } \\
\text { consistency }\end{array}$} \\
\hline Speech & \multicolumn{2}{|c|}{ Anarthria } & \multicolumn{2}{|c|}{ 2-3 words of verbal production } & \multicolumn{2}{|c|}{ presenting full complex sentences } \\
\hline MMSE & \multicolumn{2}{|c|}{ NT } & \multicolumn{2}{|c|}{ NT } & \multicolumn{2}{|c|}{$30 / 30$} \\
\hline
\end{tabular}

Iranian Rehabilitation Journal

NT: Not Testable; ROM: Range of Motion; PROM: Passive Range of Motion; MMSE: Mini-Mental State Examination.

electrophysiological investigation. The outcome and prognosis of CPM and EPM are heterogeneous; a few became functionally independent with residual deficits, and a few became entirely dependent. Some become independent with residuals deficits, and some become entirely dependent [1]. Electrophysiological and radiological examinations play an essential role in establishing such clinical conditions; however, a recent large case series highlighted that neither the severity of clinical features nor the extent of radiological and electrophysiological findings can be predictive of its prognosis [2]. Therefore, the prognostication of such condition is challenging and will be less precise. A study on 25 patients with ODS revealed some predictors associated with the favorable outcome; they were higher GCS scores upon presentation; better functional scores during hospital admission; less severe hyponatremia $(>115)$; and the absence of superadded hypokalaemia [3].
The rehabilitation approach in the reviewed patient was delivered in a customized stepwise manner; according to the clinical course, this approach depended on the clinical course. This method provides comprehensive slow stream multidisciplinary rehabilitation, focusing on preventative and maintenance management. The disabling symptoms of severe generalized rigidity, stiffness and resting tremor were addressed with Madopar pharmacotherapy [4]. Preventing the disabling complications of immobilization that hinder further functional and physical recovery is of great significance. It was demonstrated in our case; the reviewed patient has developed bilateral ankle contracture that hindered him from attaining early independent ambulation. More time and resources were required to reverse the complication that further delayed his functional recovery.

Further active multidisciplinary rehabilitation therapy that comprises thorough bio-functional assessment, fol- 
Table 2. Stepwise multidisciplinary rehabilitation strategies according to Patterson and Grabois Motor Recovery Scale

Patterson and Grabois
Motor Recovery Scale Rehabilitation Goal Rehabilitation Intervention

Comprehensive slow-stream rehabilitation strategies:

Nutrition optimization

Bladder and bowel care

Skin and integumentary care to prevent pressure injuries

Category 1 :

No return of motor function and total dependence in all ADLs*
Complications preventions and maintenance management
Cardiorespiratory physiotherapy

Proper joint positioning and protection strategies

Flexibility exercises (e.g., Stretching exercises to prevent contractures and improve ankle range of motion)

Pharmacotherapy for severe Parkinsonism signs and symptoms (Madopar $250 \mathrm{mg}$ 8-hourly)

Dysphagia management

(Swallowing re-training by stimulating swallowing reflexes and exercises.)

\begin{tabular}{|c|c|c|}
\hline $\begin{array}{c}\text { Category 2: } \\
\text { Minimal motor return } \\
\text { and total dependence in } \\
\text { all ADLs }\end{array}$ & $\begin{array}{l}\text { Promoting re-condi- } \\
\text { tioning and neuro- } \\
\text { recovery. } \\
\text { Functional Goal: } \\
\text { Minimal independence } \\
\text { level }\end{array}$ & $\begin{array}{l}\text { Stepwise re-conditioned intensive multidisciplinary rehabilitation: } \\
\text { Targeted Strengthening exercise: } \\
\text { Core muscles training of the spine extensors, lateral rotators, and abdominal girdle } \\
\text { muscles } \\
\text { Proximal lower limb muscle training of hip extensors and flexors, knee extensors } \\
\text { and calf muscle } \\
\text { Proximal upper limb muscle training of rotator cuff, forearm, and arm muscles. } \\
\text { Flexibility exercise: } \\
\text { Aggressive stretching focusing on the bilateral ankle to improve ROM } \\
\text { Aerobic and Respiratory exercises: } \\
\text { Incentive spirometry training } \\
\text { Ergometer cycling with upgraded intensity } \\
\text { Mobility Training: } \\
\text { Bed profiling training } \\
\text { Static and dynamic sitting training } \\
\text { Functional training } \\
\text { Hand dexterity training } \\
\text { Assistive adaptive device prescription: Big handle spoon } \\
\text { Transfer training: Bed to a wheelchair, wheelchair to bed } \\
\text { Swallowing re- training } \\
\text { Swallowing training: Masako exercise, Shaker exercise } \\
\text { Compensatory swallowing strategy: Head tilt and chin tuck } \\
\text { Introducing stepwise food consistency: Thin fluids- pureed- mince and moist- soft- } \\
\text { bite- solid food. } \\
\text { Speech and articulation re-training } \\
\text { Buccal- lingual- facial exercises } \\
\text { Oro-motor exercises } \\
\text { Continuation of pharmacotherapy: T. Madopar } 25 \text { mg 8-hourly }\end{array}$ \\
\hline $\begin{array}{c}\text { Category 4: } \\
\text { Independence in all } \\
\text { ADLs and some minimal } \\
\text { neurologic deficit }\end{array}$ & $\begin{array}{l}\text { Functional goal: Maxi- } \\
\text { mal Independence } \\
\text { level }\end{array}$ & $\begin{array}{l}\text { Stepwise Active intensive multidisciplinary program: } \\
\text { General core body muscle strengthening exercises } \\
\text { Resistance exercises; isokinetic and isotonic exercises } \\
\text { Aerobic exercises } \\
\text { Static cycling exercise in increasing intensity } \\
\text { Treadmill walking/running in increasing intensity } \\
\text { Mobility retraining } \\
\text { Balance and coordination training e.g., dynamic and static exercises } \\
\text { Gait training: Thread mill body weight support and over the ground gait training } \\
\text { Speech intelligibility and clarity training } \\
\text { Basic ADL retraining } \\
\text { Admission to an independent living unit for } 4 \text { days without any assistance }\end{array}$ \\
\hline
\end{tabular}


lowed by physical therapy, occupational therapy, as well as speech and language therapy, should be intensified. Such measures should be customized accordingly depending on the clinical condition's progression. A rehabilitation approach should be directed to maximize the bio-functional outcomes. This goal could be achieved via assisting complete recovery or adaptation strategies if a complete recovery is not feasible. This approach decreases the mortality rate and dependency level, promotes significant recovery, and further improves the quality of life in this population [5]. Early intensive rehabilitation was signified as a significant predictive factor for a favorable outcome in patients with LIS despite vague and variable disease outcomes [5].

\section{Conclusion}

Early intensive multidisciplinary rehabilitation interventions combined with pharmacotherapy manifested benefits to prevent complications, hasten recovery, and further maximize functional level in ODS-induced disabilities.

\section{Ethical Considerations}

\section{Compliance with ethical guidelines}

There were no ethical considerations to be considered in this research.

Funding

This research did not receive any grant from funding agencies in the public, commercial, or non-profit sectors.

\section{Authors' contributions}

Conception of the case, data collection and interpretation, drafting, and critical revision of the article: Natiara Mohamad Hashim and Fatimah Ahmedy; Critical revision of the manuscript drafting: Wan Najwa Wan Mohd Zohdi; Proofreading and copy-editing of the manuscript: Khadijah Mahmud.

\section{Conflict of interest}

The authors declared no conflicts of interest.

\section{References}

[1] Martin RJ. Central pontine and extrapontine myelinolysis: The osmotic demyelination syndromes. Journal of Neurology, Neurosurgery, and Psychiatry. 2004; 75 Suppl 3(Suppl 3):iii22-8. [DOI:10.1136/jnnp.2004.045906] [PMID] [PMCID]

[2] Menger H, Jörg J. Outcome of central pontine and extrapontine myelinolysis $(n=44)$. Journal of Neurology. 1999; 246(8):700-5. [DOI:10.1007/s004150050435] [PMID]

[3] Kallakatta RN, Radhakrishnan A, Fayaz RK, Unnikrishnan JP, Kesavadas C, Sarma SP. Clinical and functional outcome and factors predicting prognosis in osmotic demyelination syndrome (central pontine and/ or extrapontine myelinolysis) in 25 patients. Journal of Neurology, Neurosurgery, and Psychiatry. 2011; 82(3):326-31. [DOI:10.1136/jnnp.2009.201764] [PMID]

[4] Tinker R, Anderson MG, Anand P, Kermode A, Harding AE. Pontine myelinolysis presenting with acute parkinsonism as a sequel of corrected hyponatraemia. Journal of Neurology, Neurosurgery, and Psychiatry. 1990; 53(1):87-8. [DOI:10.1136/jnnp.53.1.87-a] [PMID] [PMCID]

[5] Laureys S, Pellas F, Van Eeckhout P, Ghorbel S, Schnakers C, Perrin F, et al. The locked-in syndrome: What is it like to be conscious but paralyzed and voiceless? Progress in Brain Research. 2005; 150:495-511. [DOI:10.1016/S0079-6123(05)50034-7] [PMID] 